\title{
Cambios en el uso del suelo en el municipio de Álamos, Sonora - México
}

\author{
Adán Guillermo Ramírez García \\ Centro Regional Universitario del Noreste \\ Universidad Autónoma Chapingo, Ciudad Obregón, Sonora - México \\ gramirezg@taurus.chapingo.mx
}

Recepción: 23/05/2016

Aceptación: 20/06/2016

\section{Resumen}

En el marco del desarrollo territorial, este trabajo analizó el cambio de uso del suelo y vegetación en el municipio de Álamos, estado de Sonora - México, para el periodo comprendido entre los años 1980 y 2001 . El área de estudio caracterizó un rezago productivo, el alto índice de marginación y la sobreexplotación de los recursos naturales principalmente a causa de las actividades agropecuarias.

El objetivo fue identificar la magnitud y distribución espacial del cambio de uso del suelo. Para la obtención del mapa de cambio de uso del suelo se utilizó la cartografía existente elaborada en distintas fechas y por diferentes autores, y se realizó una sobreposición mediante el empleo de un sistema de información geográfico (SIG), utilizando el programa ArcView GIS versión 3.2. En el periodo de estudio, los resultados muestran que la agricultura de temporal disminuyó de 73688 a 57588 hectáreas; los pastizales cultivados aumentaron en un 1.050\%. En el caso de los matorrales, prácticamente todos perdieron superficie y en algunos casos desaparecieron.

En cuanto a los bosques, el de pino-encino fue el único que perdió superficie (56\%) al cambiar de 47019 a 20656 hectáreas. La selva baja caducifolia y subcaducifolia tuvieron una pérdida de $23 \%$ de su superficie. La superficie ocupada por los cuerpos de agua disminuyó en aproximadamente 40\%, al reducir su superficie de 7963 a 4747 hectáreas. Sin duda la importancia económica de la actividad ganadera en el municipio es uno de los factores que explican los resultados encontrados.

Palabras clave: SIG, ganadería, deforestación, mapas, área natural protegida.

\begin{abstract}
In the context of territorial development, this work analyzed the change of land use and vegetation in the municipality of Alamos, state of Sonora - Mexico, for the period between 1980 and 2001. The area of study was characterized by a productive lag. The high rate of marginalization and the overexploitation of natural resources mainly due to agricultural activities.

The objective was to identify the magnitude and spatial distribution of land use change. In order to obtain the land use change map, the existing cartography was used in different dates and by different authors, and an overlay was made using a geographic information system (GIS), using ArcView GIS version 3.2. In the study period, the results show that temporary agriculture decreased from 73688 to 57588 hectares; Cultivated pastures increased by $1,050 \%$. In the case of the bushes, practically all lost surface and in some cases disappeared.

As for the forests, the pine-oak was the only one that lost surface (56\%) when changing from 47019 to 20656 hectares. The low deciduous and subcaducifolia forest had a loss of $23 \%$ of its surface. The area occupied by bodies of water decreased by approximately 40\%, reducing its area from 7963 to 4747 hectares. Without a doubt the economic importance of the livestock activity in the municipality is one of the factors that explain the results found.
\end{abstract}

Key words: SIG (by its acronyms in Spanish), livestock, maps, protected natural area. 


\section{Introducción}

En México, las comunidades rurales dependen en gran medida de sus recursos naturales; sin embargo, debido a las condiciones de pobreza en que se encuentran, se ven obligadas a explotar intensivamente sus recursos y a utilizar en actividades productivas predios que no tienen el potencial adecuado (Carabias et al., 1994). En este sentido, el ordenamiento territorial (OT) puede ser valioso como herramienta para la planeación y gestión del territorio, orientado al desarrollo sostenible desde una perspectiva integral. Constituye un proceso de planeación con un enfoque integral multifactorial que refleja la naturaleza compleja y dinámica del territorio, es decir, lo entiende como un sistema en el cual interactúan - a diferentes escalas - componentes naturales, socioculturales, económicos, urbanoregionales y políticos cuyas relaciones varían a través del tiempo (Sánchez et al., 2013).

En la Ley General del Equilibrio Ecológico y Protección al Ambiente (LGEEPA) de los Estados Unidos Mexicanos, se concibe el ordenamiento ecológico como instrumento de la política ambiental, encaminado a regular o inducir el uso del suelo y las actividades productivas, con el fin de lograr la protección del medio ambiente y la preservación y el aprovechamiento sustentable de los recursos naturales, a partir del análisis de las tendencias de deterioro y las potencialidades de aprovecha- miento de los mismos (Artículo 3, Fracción XIII) (Sedue, 1988).

Toledo (1996), señala que la noción de comunidad sustentable descansa entre otros postulados, en el usufructo ecológicamente adecuado de los recursos naturales locales; es decir, un usufructo basado en la correcta discriminación de las unidades ambientales, el reconocimiento de sus vocaciones productivas y su capacidad de sustentación, y el uso eficiente de la energía. Sólo así puede garantizarse una producción sostenida (o permanente), basada en la renovabilidad natural de los sistemas ecológicos y geográficos.

Por lo que la ampliación de la frontera agrícola, la intensificación de la producción de las tierras actualmente dedicadas a labores agrícolas, y la promoción de éstas y otras actividades bajo esquemas de desarrollo sostenible exigen obtener cada vez datos más completos acerca de los recursos naturales; y determinar cuáles son los métodos más apropiados para desarrollar y utilizar cada uno de esos recursos. Uno de los prerrequisitos de una planificación eficiente y de un desarrollo económico exitoso lo constituye - entre otros elementos - el conocimiento de los suelos, sus características, sus limitaciones, sus potenciales y su distribución geográfica; así como el uso actual del suelo, para asignar y ordenar con base en esos atributos los usos óptimos de cada porción de un territorio (Vásquez, 1996). 
En este sentido, el análisis del cambio de uso del suelo permite conocer el estado del ecosistema, área o lugar, dado que refleja los cambios que se presentan en un espacio multitemporal, así como las influencias antropogénicas o naturales que han provocado esos cambios permitiendo además conocer las causas. El uso de suelo tiene gran influencia en el proceso de infiltración, distribución del agua en el suelo y evaporación afectada por la cobertura vegetal (De et al. 2003).

Estudiar la magnitud, dinámica y causalidad de los procesos de cambio de cobertura y uso del suelo es una tarea prioritaria (Bocco et al., 2001). En un estudio de cambio de uso de suelo (Semarnat, 2008), a nivel nacional, considerando la carta de uso potencial generada por INEGI a escala 1:1000 000 como la vegetación original, se reporta una pérdida de 222 mil km² de selva, 129 mil de bosque, $51 \mathrm{mil}$ de matorrales y 60 mil de pastizales. Tan solo de 1970 a 1993, catorce millones de hectáreas (ha) ${ }^{1}$ de bosques, selvas, matorrales y pastizales fueron alterados o remplazados por comunidades secundarias a un ritmo de $823 \mathrm{mil}$ hectáreas año ${ }^{-1(*)}$, afectando principalmente a bosques y selvas (276 mil hectáreas $\mathrm{año}^{-1} \mathrm{y}$ 341 mil hectáreas año-1, respectivamente). Su análisis permite entender las causas y consecuencias de las tendencias de los procesos de degradación, desertificación, disminución de la biodiversidad y, en general, pérdida del capital natural y cultural (Mas et al., 2009).

Masera et al. (1997), afirman que México se encuentra entre los más deforestados del mundo. Sin embargo, no existen análisis cuantitativos de la importancia relativa de estos factores con el cambio de la cobertura y el uso del terreno, ya que las interpretaciones de cómo éstos interactúan para estimular el cambio varían ampliamente de una región a otra (Skole et al., 1994, Kummer y Turner, 1994). Según Lambin (1997), la mayor parte de los cambios ocurridos en ecosistemas terrestres se debe a conversión de la cobertura del terreno, degradación del mismo e intensificación de su empleo. Estos procesos, que usualmente se engloban en lo que se conoce como deforestación o degradación forestal, se asocian a impactos ecológicos importantes en prácticamente todas las escalas.

Entender el impacto que ocasiona el cambio de uso y cobertura del terreno significa estudiar factores ambientales y socioeconómicos. El cambio de uso de suelo provocado por actividades antropogénicas tiene influencia en los procesos naturales como recarga de acuíferos, escurrimiento superficial y pérdida de suelo, entre otros, de ahí la importancia de conocer la dinámica de dicho cambio y sus posibles orígenes (Trucíos, 2011). 
En la escala temporal de décadas, las actividades humanas que impactan el uso de suelo son el factor clave en la forma que adoptan los cambios del paisaje. Algunos de ellos son provocados por prácticas específicas de manejo y otros por las fuerzas sociales, políticas y económicas que controlan los usos de suelo (Medley et al., 1995 y Pan et al., 1999). Los patrones de deforestación varían notablemente por regiones. Esos factores ambientales y socioeconómicos determinan en forma importante el patrón ocurrido en cada región en particular (Masera, 1996).

Dado que los procesos de cambio en la cobertura y uso del suelo se encuentran en el centro de la investigación ambiental actual (Bocco et al., 2000), debido a las implicaciones que conllevan en la pérdida de hábitat, diversidad biológica, servicios ambientales y capacidad productiva de los ecosistemas, es necesario responder a los siguientes cuestionamientos: ¿por qué, dónde y cuándo ocurre el cambio en el uso del suelo? Estas interrogantes se abordan a través de metodologías apoyadas en el uso de sistemas de información geográfica y análisis estadístico espacial (Sandoval y Oyarzun, 2003). El objetivo fue identificar la magnitud y distribución espacial del cambio de uso del suelo para el municipio de Álamos, Sonora - México.

Acerca de los factores que influyen en el cambio de uso de suelo en el municipio, Ramírez
(2005) considera que el área de estudio se caracteriza por el importante rezago productivo, el alto índice de marginación y la sobreexplotación de los recursos naturales, principalmente a causa de las actividades agropecuarias. En el caso particular de la ganadería, destaca la superficie municipal que utiliza, la cual corresponde a 92\%. En el aspecto social, se sabe que $14 \%$ de los productores ganaderos son privados y que detentan $48 \%$ del área de agostadero; en tanto que el $86 \%$ de lo correspondiente al sector social, usufructúa el 52\% restante. Es una ganadería extensiva de libre pastoreo; produce principalmente becerros al destete, y responde básicamente a los requerimientos del mercado norteamericano. Los factores que han tenido más influencia sobre la evolución de la ganadería en el municipio y que han estado presentes en toda la entidad son de tipo climático y económico.

El primer caso tiene que ver con la sequía relativa de precipitaciones por debajo de lo normal, que se ha prolongado por ocho años, $y$ que obligó a los rancheros a desalojar mucho de su ganado hasta quedarse con un hato pequeño para poder sostenerlo con menos agua y pasto dentro de los agostaderos.

Dadas las características climáticas, edáficas y de flora natural, se sabe que la recomendación técnica para el pastoreo es de 28 hectáreas por unidad animal (Cotecoca, 1974). No obstante se estima que hay una sobrecarga de 
290\%. Aun considerando las praderas existentes y los esquilmos agrícolas, difícilmente se cubren las necesidades forrajeras para evitar el sobrepastoreo. La falta de agua de lluvia es el problema de mayor importancia, ya que repercute en la falta de disponibilidad de forraje. Igualmente, por la escasa recarga de los mantos freáticos en temporadas de estiaje, se acarrea el agua en vehículos automotores, implicando una inversión considerable y gasto de operación, que impactan los costos de producción y afecta la sobrevivencia del ganado.

Esta investigación tuvo el propósito de responder las siguientes preguntas: ¿qué usos del suelo han cambiado en el periodo comprendido entre los años de 1980 y 2000?, ¿en dónde se localizan? y ¿cuáles presentan incrementos o pérdida y a cuánto equivalen? Las inquietudes surgen a partir de la comparación de documentos cartográficos correspondientes a ambas fechas, donde se visualizan permanencias y modificaciones en el uso del suelo. En este contexto, el objetivo es identificar la distribución espacial y analizar la dinámica de cambio de uso del suelo en el municipio de Álamos, Sonora - México.

\section{Materiales y métodos}

El área de estudio se ubicó al sureste del estado de Sonora, México; entre los paralelos $27^{\circ} 46.2^{\prime}$ y $26^{\circ} 23.4^{\prime}$ de latitud norte y entre los $108^{\circ} 25.2^{\prime}$ y $109^{\circ} 15.6^{\prime}$ de longitud oeste; tiene una extensión de $6,947.47 \mathrm{~km}^{2}$ ( ver Figura 1).
Orografía: $70 \%$ de la superficie es accidentada, se localiza en la región noreste y zonas aisladas donde el terreno está surcado por las derivaciones de la Sierra Madre Occidental. La altura sobre el nivel del mar varía de 500 a 2,000 metros. En cuanto a la hidrología, el río Mayo cruza de oriente a poniente el municipio procedente del estado de Chihuahua. Álamos presenta cuatro grupos climáticos, de los cuales los secos ocupan la mayor proporción de la superficie, abarcan $52.44 \%$; los semicálidos subhúmedos $41.90 \%$, los templados subhúmedos $5.26 \%$ y los cálidos subhúmedos $0.40 \%$. Sus ocho unidades de suelo en orden de importancia son: regosol (45\%), litosol (27\%), cambisol (17\%), feozem (4\%), vertisol $(3 \%)$, xerosol $(2 \%)$, yermosol $(1 \%)$ y fluvisol (1\%).

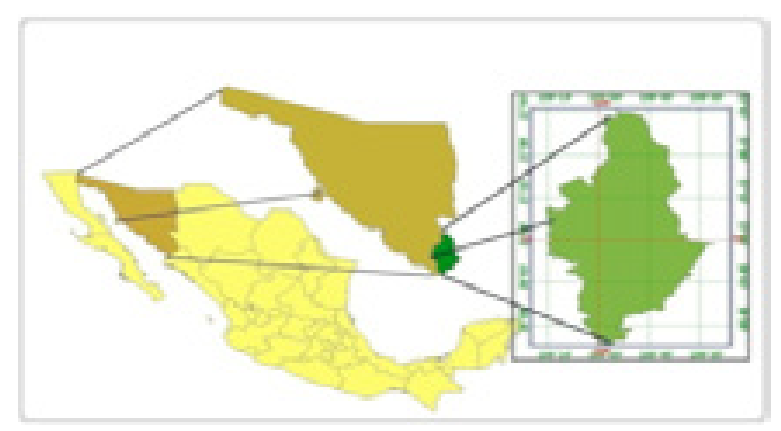

Figura 1. Ubicación geográfica de la zona de estudio.

El estudio tuvo como periodo de análisis el comprendido entre los años de 1980 y 2000. Dado que en el año de 1996 se decretó el Área de Protección de Flora y Fauna (APFF) Sierra de Álamos-Río Cuchujaqui - México, por su alta diversidad y riqueza biológica al presentar 
diversos tipos de vegetación como selva baja caducifolia, matorral espinoso sinaloense, bosques de encino, bosques de pino encino y zonas riparias. La selva baja caducifolia, alcanza aquí su límite de distribución más norteño en el planeta; y por jugar un papel importante en la recarga de acuíferos en los cuerpos de agua locales. Este estudio prentendió dejar constancia de los cambios de uso del suelo previos al decreto de la APFF, por lo que se espera sea un referente para estudios similares.

Dada la necesidad de integrar la investigación multi e interdisciplinaria, se hizo necesario encontrar herramientas que permitieran el análisis de información con base espacial. En este sentido, los Sistemas de Información Geográfica (SIG)² fueron idóneos para cuantificar el cambio en el uso del suelo, ya que se pudo utilizar información variada y de distintas fuentes.

Los SIG están diseñados para trabajar con datos referenciados con respecto a coordenadas espaciales o geográficas, así como con distintas bases de datos de manera integrada, permitiendo así generar información gráfica (mapas) útil para la toma de decisiones en la planificación territorial. Los mapas simplificaron varios aspectos de la realidad de la zona de estudio, cuyo objetivo fue reconocer la existencia de patrones espaciales sobre algún fenómeno de interés.
De acuerdo con Monterroso et al. (2006), para el estudio de cambio de uso del suelo existen diferentes técnicas de análisis multitemporal, como las comparaciones estadísticas de diferentes fechas, el estudio de regiones $y$ extrapolación, la comparación de cartografía elaborada y el análisis por medio de imágenes de satélite. En este caso se utilizó la cartografía existente y las imágenes de satélite, por la exactitud que proporcionó a la combinación de estas técnicas.

Los problemas más comunes asociados con la interpretación de la información del uso del suelo son la incompatibilidad e inconsistencia de la terminología y el desarrollo de la utilidad de los sistemas de clasificación (Nunnally y Witmer, 1970). Con el fin de solventar esta situación, para la obtención del mapa de cambio de uso del suelo y vegetación se utilizó la cartografía existente, elaborada en distintas fechas y por diferentes autores: Uso de suelo y vegetación Serie I (INEGI, 1980), Uso de Suelo y vegetación Serie II (INEGI, 1993) e Inventario Forestal Nacional (SemarnatUNAM, 2001). Con la cartografía señalada se realizó una sobreposición mediante el SIG ArcView GIS, versión 3.2. Lo anterior generó un mapa de cambio espacial y temporal que reflejó los tipos y grados de cambio.

Para la sobreposición de los mapas temáticos fue necesario homologar las distintas clases y

2. A lo largo de este artículo, el autor también se referirá a este término mediante su sigla. 
leyendas señaladas en cada mapa, ya que en algunas de ellas (Semarnat y UNAM, 2001) la clasificación de la vegetación se encontraba muy detallada y en las otras (Inegi, 1980 y 1993) muy general. Los criterios para la homologación fueron acordes a lo propuesto por el Instituto de Geografía de la Universidad Nacional Autónoma de México, UNAM (Semarnat, 2008). De esta manera se obtuvo una nomenclatura equivalente y comparable paras las distintas cartografías, como se observa en el tabla 1.

Una vez conformada la nomenclatura se obtuvieron las estadísticas para cada tipo de vegetación y uso de suelo para cada una de las fechas, lo que permitió observar las modificaciones importantes en cuanto a superficie ocupada en los diferentes periodos. El mapa de condición actual de la vegetación se obtuvo mediante el análisis e interpretación de la publicación de cobertura de uso de suelo y vegetación más reciente, el Inventario Forestal Nacional $(\text { IFN })^{3}$ (Semarnat y UNAM, 2001). Además, fue necesario incluir en el análisis la imagen de satélite del área de estudio (Geocover, 2000) utilizando el SIG.

El análisis e interpretación de la base de datos del Inventario Nacional Forestal se llevó a cabo verificando cada una de las clases señaladas de uso del suelo o vegetación. De esta manera se caracterizaron cuatro categorías de condición de la vegetación: natural, perturbada, sustituida y utilizada. Éstas tienen como objetivo determinar el significado ecológico en la estructura del paisaje a la cual pertenecen, es decir, la función o el estadio de evolución que presentan según el sistema fisiográfico al que pertenecen. Cabe señalar que fue necesaria la sobreposición cartográfica del INF con la imagen de satélite para evaluar espacialmente si realmente correspondían a la clasificación asignada en la cartografía.

Las comunidades vegetales o usos del suelo caracterizados bajo las cuatro categorías de condición de la vegetación obedecieron a los siguientes criterios:

a. Condición natural: Se refiere a toda comunidad vegetal señalada dentro del IFN que no tiene un grado de perturbación, es decir, sin ningún tipo de vegetación secundaria. Se verificó además que en la imagen de satélite no se mostrara algún indicio de degradación de la misma, ya sea por erosión, deforestación, incendios, etc.

b. Condición perturbada: Esta representa a toda comunidad vegetal que de acuerdo al IFN se encuentra con algún tipo de vegetación secundaria, ya sea herbácea y/o arbustiva. Se refiere a una vegetación con algún grado de perturbación en referencia

3. Dentro de este documento, el autor también se referirá a este término mediante su sigla. 
a su condición natural. Se comprobó además si en la imagen de satélite se observaba algún tipo de degradación de la misma.

c. Condición sustituida: Es todo aquel uso del suelo o comunidad vegetal en el que se encontraba cambiado el uso prioritario de suelo. En esta categoría se consideraron principalmente los pastizales inducidos así como también las áreas sin vegetación aparente. Lo anterior, debido a que estos usos de suelo han remplazado ya sea por intervención del hombre o de manera natural la vegetación del lugar. Sus linderos también fueron corroborados con la imagen de satélite.

d. Condición utilizada: Se refiere a los usos del suelo o comunidades vegetales en los que se encontraba de acuerdo al IFN, cualquier tipo de agricultura y/o pastizal cultivado. Esta condición se incluyó como una categoría diferente a las anteriores, ya que en ellos se produce algún tipo de producto y/o alimento para el consumo humano.

e. Por último, los cuerpos de agua y los asentamientos humanos permanecieron como tales en la clasificación del mapa de condición de la vegetación.

Para la validación se realizaron recorridos de campo por todo el municipio, así como entrevistas con actores clave, funcionarios del municipio y personal del Área de protección de flora y fauna Sierra de Álamos RíoCuchujaqui, México.

\section{Resultados y discusión}

Los resultados sobre el cambio del uso del suelo (Figura 2 y Tabla 1 y 2), se describen en los siguientes párrafos:

\section{Agricultura}

La agricultura de temporal fue el uso de suelo que más disminuyó en comparación con la de riego; la superficie de cambio fue de 73688 a 57 588ha que representó una disminución de $21 \%$. La causa principal fue el incremento de los pastizales cultivados que cubren actualmente 23 295ha provenientes de la agricultura de temporal. Por otra parte, el incremento mayor de la superficie ocupada por la agricultura proviene de 18 329ha de selva baja caducifolia y subcaducifolia con vegetación secundaria. Todas las áreas de agricultura de temporal señaladas en la cartografía de la década de 1980 ya no aparecen en la del año 2000; desaparecieron por completo, aunque aparecieron nuevas en diversos lugares del municipio. Con relación a la de riego, esta perdió $4 \%$ al cambiar de 3 490ha en el año de 1980 a 3333 ha en el año 2000. La mayor superficie disminuida obedece al incremento en algunas zonas de la agricultura de temporal con 2019 ha. La de riego obtuvo más al ganarla de las comunidades de matorral sarcocaule con vegetación secundaria, al trasformar 1470 ha. 


\section{Pastizales}

El principal cambio en el uso del suelo y vegetación que se dio fue hacia el pastizal cultivado. El aumento de su superficie fue de 1 050\% respecto a la del año de 1980: De 7538 a 86718 ha. Lo anterior significa un desplazamiento en su mayor parte de la agricultura de temporal, debido a que 23295 ha dedicadas a esta actividad fueron convertidas a pastizales cultivados. De igual forma, las comunidades de vegetación de selva baja caducifolia y subcaducifolia vieron disminuidas sus superficies sustancialmente, ya que cambiaron en el mismo periodo $22564 \mathrm{ha}$, principalmente para el establecimiento de pastizales cultivados.

A este cambio también se atribuye el desplazamiento de 11 843ha de matorral sarcocaule al que casi erradican, reduciéndolo a 391ha. El pastizal inducido fue también de los que mayor superficie aumentó: $304 \%$, al cambiar de 10001 a 40 431ha, ganándolas principalmente a la selva baja caducifolia y subcaducifolia (10 202ha), al matorral sarcocaule (8 $459 \mathrm{ha}$ ) y a la selva baja caducifolia y subcaducifolia con vegetación secundaria (7 562ha). Sus principales pérdidas de superficie han sido ante el pastizal cultivado.

\section{Matorrales}

A excepción del sarcocaule con vegetación secundaria, todas las demás clasificaciones de matorral (sarcocaule, mezquital y mezquital con vegetación secundaria) perdieron superficie. En el periodo de estudio, el mezquital con vegetación secundaria desapareció, y sólo se observan algunos relictos de mezquital natural y matorral sarcocaule.

El mezquital fue desplazado principalmente por el pastizal cultivado y la agricultura de riego (977 y 924ha, respectivamente), y el mezquital con vegetación secundaria fue transformado en 59\% de su superficie en selva baja espinosa con vegetación secundaria. Sin embargo, el mezquital obtuvo 310ha de la selva baja caducifolia y subcaducifolia con vegetación secundaria, convirtiéndose así en su principal aportador. Con relación al matorral sarcocaule, tuvo una pérdida de $100 \%$, debido principalmente a la apertura de 11843 ha de pastizal cultivado dentro de este tipo de vegetación así como a perturbaciones sufridas durante el transcurso de estos años, ya que 8 948ha pasaron a ser matorral sarcocaule con vegetación secundaria. El matorral sarcocaule no tuvo ninguna aportación por parte de los demás tipos de vegetación por lo cual disminuyó notablemente.

\section{Bosques}

De acuerdo a la cartografía de 1980, originalmente sólo se encontraban tres tipos de bosque: de pino-encino, de encino-pino y de encino. Estos tipos de vegetación generaron el bosque de pino al eliminar algunos encinos de los bosques con dichas asociaciones. Con 
esto se generaron también perturbaciones que ocasionaron la aparición de vegetación secundaria asociada.

El bosque de pino-encino fue el único que perdió superficie (56\%) al cambiar de 47019 a 20 656ha. Esta fue mayormente ocupada por el bosque de pino con 1 183ha de ganancia, mientras que el de encino aumentó 6 103ha, además de que se perturbaron $6443 \mathrm{ha}$ de este bosque. Lo anterior generó el bosque de pino-encino con vegetación secundaria y 4680 ha que formaron el bosque de encino con vegetación secundaria.

\section{Selvas}

La selva baja caducifolia y subcaducifolia son las más extensas en el municipio (40.33\%), y la pérdida de $23 \%$ de su superficie original dio origen a 15 936ha de selva baja espinosa y 63 579ha de selva baja caducifolia y subcaducifolia con vegetación secundaria. Estas a su vez dieron origen a la selva baja espinosa con vegetación secundaria. La selva baja caducifolia y subcaducifolia con vegetación secundaria se vio favorecida en $5 \%$ al aumentar su superficie de 93414 a 98 164ha.

\section{Otros usos del suelo y vegetación}

Entre los años 1980 y 2000, la superficie ocupada por los cuerpos de agua disminuyó 40\%, al reducir su superficie de 7963 a 4 747ha. Esta reducción fue aprovechada principalmente por el pastizal cultivado y la selva baja caducifolia y subcaducifolia con vegetación secundaria (1 786 y 901 ha, respectivamente). Sin embargo, también tuvo ganancias al desplazarse principalmente en 111 ha ocupadas por pastizal inducido y 88 ha de selva baja caducifolia y subcaducifolia con vegetación secundaria.

En cuanto a los asentamientos humanos se han destinado 547ha para dicho fin, la mayoría de las cuales proviene de zonas de agricultura de temporal y de selva baja caducifolia y subcaducifolia con vegetación secundaria (273 y 269ha, sucesivamente). Se tienen además 52 ha sin vegetación aparente, de las cuales 36 eran selva baja caducifolia y subcaducifolia y 15 cuerpo de agua.

De acuerdo con Camacho et al. (2011), es indudable que el desarrollo territorial enfrenta un reto importante para que las políticas públicas impulsen el manejo sustentable de los recursos naturales y estrategias que contribuyan al desarrollo rural. Es indispensable realizar la validación en campo de las coberturas de uso para llegar a una clasificación de la imagen lo más apegada a la realidad, los resultados aportan una metodología adecuada y replicable para la evaluación y análisis de la dinámica del cambio de uso del suelo con la finalidad de explorar posibles tendencias de cambio, y la identificación de ventanas para estudiar los procesos de cambio a mayor detalle debido a sus efectos diferenciales sobre el ambiente. Asimismo, es necesario considerar 
que la mayor degradación ambiental se alcanza cuando la magnitud de los daños sobrepasa la capacidad de los mecanismos naturales del ambiente para regenerarse en cuanto a sus estructuras y procesos ecológicos, que permiten la permanencia del potencial natural y de los servicios ambientales que proporciona.
Finalmente, cualquier propuesta de desarrollo territorial requiere del análisis del cambio de uso del suelo para iniciar el proceso de planeación que tenga como objetivo evaluar $\mathrm{y}$ programar el uso del suelo, y el manejo de los recursos naturales para preservar y restaurar el equilibrio ecológico sin demeritar el nivel y calidad de vida de los pobladores.

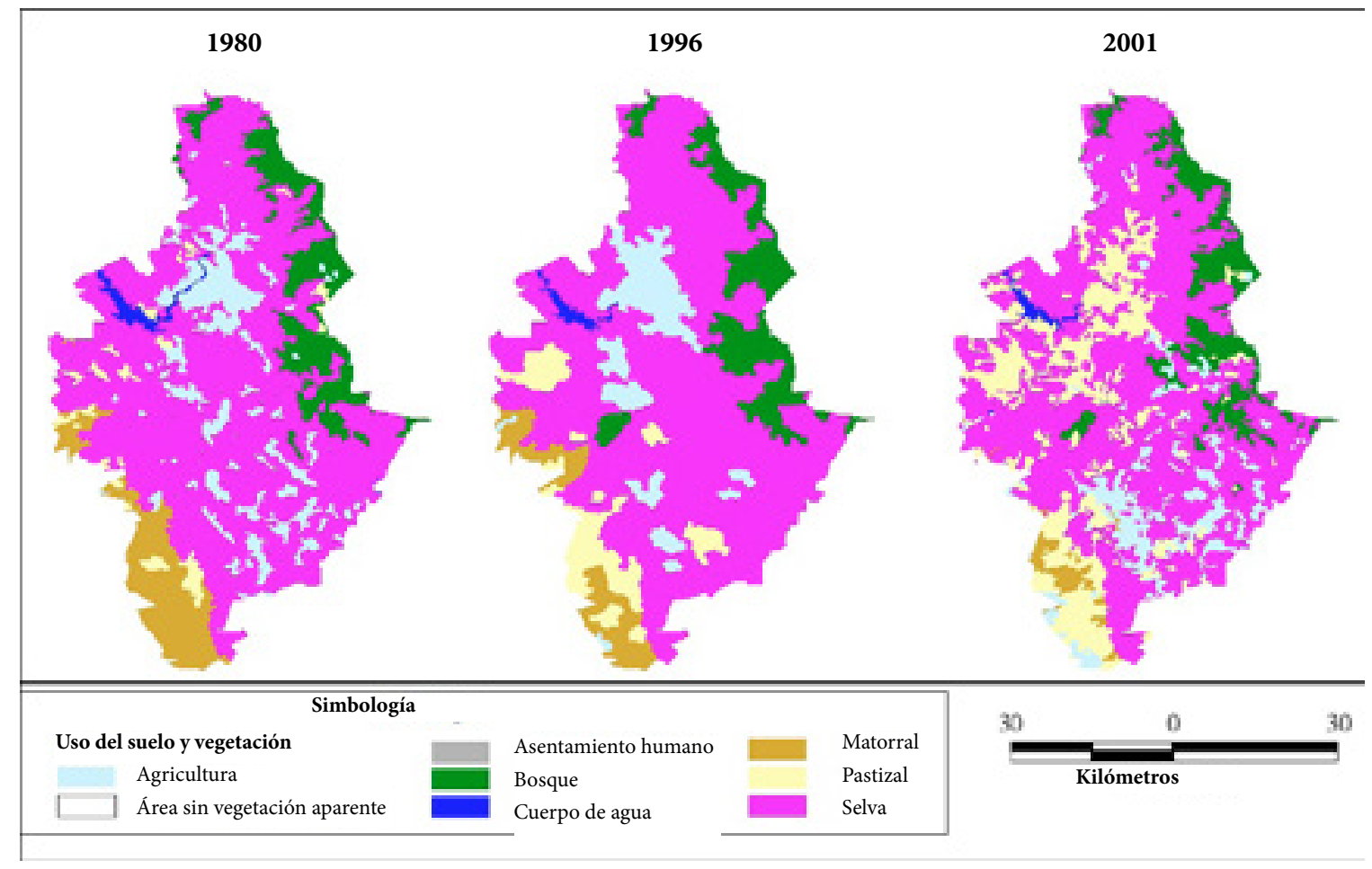

Figura 2. Uso del suelo y vegetación de acuerdo a la cartografía existente en distintas fechas. 
Tabla 1. Nomenclatura utilizada para la homologación de las distintas cartografías

\begin{tabular}{|c|c|c|c|c|}
\hline $\begin{array}{c}\text { Año / } \\
\text { Formación }\end{array}$ & 2000 & 1996 & 1980 & Clases usadas \\
\hline \multirow{2}{*}{ Agricultura } & $\begin{array}{l}\text { Agricultura (incluye } \\
\text { riego eventual) }\end{array}$ & $\begin{array}{l}\text { Agricultura } \\
\text { de riego }\end{array}$ & $\begin{array}{l}\text { Agricultura } \\
\text { de riego }\end{array}$ & Agricultura de riego \\
\hline & $\begin{array}{l}\text { Agricultura de temporal } \\
\text { con cultivos anuales }\end{array}$ & $\begin{array}{l}\text { Agricultura } \\
\text { de temporal }\end{array}$ & $\begin{array}{l}\text { Agricultura } \\
\text { de temporal }\end{array}$ & $\begin{array}{l}\text { Agricultura } \\
\text { de temporal }\end{array}$ \\
\hline \multirow{2}{*}{ Pastizal } & Pastizal cultivado & $\begin{array}{l}\text { Pastizal } \\
\text { cultivado }\end{array}$ & $\begin{array}{l}\text { Pastizal } \\
\text { cultivado }\end{array}$ & Pastizal cultivado \\
\hline & Pastizal inducido & - & $\begin{array}{l}\text { Pastizal } \\
\text { inducido }\end{array}$ & Pastizal inducido \\
\hline \multirow{4}{*}{ Matorral } & $\begin{array}{l}\text { Mezquital (incluye } \\
\text { huizachal) }\end{array}$ & Mezquital & Mezquital & Mezquital \\
\hline & - & - & $\begin{array}{l}\text { Mezquital con } \\
\text { vegetación } \\
\text { secundaria }\end{array}$ & $\begin{array}{l}\text { Mezquital con } \\
\text { vegetación } \\
\text { secundaria }\end{array}$ \\
\hline & Matorral sarcocaule & $\begin{array}{l}\text { Matorral } \\
\text { sarcocaule } \\
\text { Matorral } \\
\text { crasicaule }\end{array}$ & $\begin{array}{l}\text { Matorral } \\
\text { sarcocaule }\end{array}$ & Matorral sarcocaule \\
\hline & $\begin{array}{l}\text { Matorral sarcocaule con } \\
\text { vegetación secundaria }\end{array}$ & - & $\begin{array}{l}\text { Matorral } \\
\text { sarcocaule } \\
\text { con } \\
\text { vegetación } \\
\text { secundaria }\end{array}$ & $\begin{array}{l}\text { Matorral sarcocaule } \\
\text { con vegetación } \\
\text { secundaria }\end{array}$ \\
\hline
\end{tabular}




\begin{tabular}{|c|c|c|c|c|}
\hline $\begin{array}{c}\text { Año / } \\
\text { Formación }\end{array}$ & 2000 & 1996 & 1980 & Clases usadas \\
\hline \multirow{5}{*}{ Bosque } & Bosque de pino & $\begin{array}{l}\text { Bosque de } \\
\text { pino }\end{array}$ & - & Bosque de pino \\
\hline & $\begin{array}{l}\text { Bosque de pino - encino } \\
\text { (incluye encino - pino) }\end{array}$ & - & $\begin{array}{l}\text { Bosque de } \\
\text { encino - pino } \\
\text { Bosque de } \\
\text { pino - encino }\end{array}$ & $\begin{array}{l}\text { Bosque de pino - } \\
\text { encino (incluye en- } \\
\text { cino - pino) }\end{array}$ \\
\hline & $\begin{array}{l}\text { Bosque de pino - encino } \\
\text { (incluye encino - pino) } \\
\text { con vegetación secun- } \\
\text { daria }\end{array}$ & - & - & $\begin{array}{l}\text { Bosque de pino } \\
\text { - encino (incluye } \\
\text { encino - pino) con } \\
\text { vegetación secun- } \\
\text { daria }\end{array}$ \\
\hline & Bosque de encino & $\begin{array}{l}\text { Bosque de } \\
\text { encino }\end{array}$ & $\begin{array}{l}\text { Bosque de } \\
\text { encino }\end{array}$ & Bosque de encino \\
\hline & $\begin{array}{l}\text { Bosque de encino con } \\
\text { vegetación herbácea y } \\
\text { arbustiva }\end{array}$ & - & - & $\begin{array}{l}\text { Bosque de encino } \\
\text { con vegetación her- } \\
\text { bácea y arbustiva }\end{array}$ \\
\hline \multirow{4}{*}{ Selva } & $\begin{array}{l}\text { Selva baja caducifolia y } \\
\text { subcaducifolia }\end{array}$ & $\begin{array}{l}\text { Selva baja } \\
\text { caducifolia }\end{array}$ & $\begin{array}{l}\text { Selva baja ca- } \\
\text { ducifolia }\end{array}$ & $\begin{array}{l}\text { Selva baja caducifo- } \\
\text { lia y subcaducifolia }\end{array}$ \\
\hline & $\begin{array}{l}\text { Selva baja caducifolia y } \\
\text { subcaducifolia con ve- } \\
\text { getación secundaria y } \\
\text { arbustiva y herbácea }\end{array}$ & - & $\begin{array}{l}\text { Selva baja ca- } \\
\text { ducifolia con } \\
\text { vegetación } \\
\text { secundaria }\end{array}$ & $\begin{array}{l}\text { Selva baja caducifo- } \\
\text { lia y subcaducifolia } \\
\text { con vegetación se- } \\
\text { cundaria }\end{array}$ \\
\hline & Selva baja espinosa & $\begin{array}{l}\text { Selva baja } \\
\text { espinosa }\end{array}$ & - & Selva baja espinosa \\
\hline & $\begin{array}{l}\text { Selva baja espinosa con } \\
\text { vegetación secundaria } \\
\text { arbustiva y herbácea }\end{array}$ & - & - & $\begin{array}{l}\text { Selva baja espinosa } \\
\text { con vegetación se- } \\
\text { cundaria arbustiva } \\
\text { y herbácea }\end{array}$ \\
\hline \multirow{3}{*}{$\begin{array}{l}\text { Otros usos } \\
\text { del suelo y } \\
\text { vegetación }\end{array}$} & $\begin{array}{l}\text { Área sin vegetación apa- } \\
\text { rente }\end{array}$ & - & - & $\begin{array}{l}\text { Área sin vegetación } \\
\text { aparente }\end{array}$ \\
\hline & Asentamiento humano & - & - & $\begin{array}{l}\text { Asentamiento hu- } \\
\text { mano }\end{array}$ \\
\hline & Cuerpo de agua & $\begin{array}{l}\text { Cuerpo de } \\
\text { agua }\end{array}$ & $\begin{array}{l}\text { Cuerpo de } \\
\text { agua }\end{array}$ & Cuerpo de agua \\
\hline
\end{tabular}

Fuente: Elaboración propia a partir de Semarnat, 2004. 
Tabla 2. Cambios de uso del suelo en el municipio de Álamos, Sonora - México

\begin{tabular}{|c|c|c|c|c|c|}
\hline \multirow{2}{*}{ Agricultura } & \multicolumn{5}{|c|}{ Área(ha) por año } \\
\hline & 1980 & 1996 & 2001 & Cambio $^{\dagger}$ & Porcentaje $^{\dagger}$ \\
\hline De riego & 3490.06 & 1056.10 & 3333.35 & -156.71 & -4.49 \\
\hline De temporal & 73688.09 & 61597.15 & 57588.10 & -16099.99 & -21.85 \\
\hline \multirow{2}{*}{ Pastizal } & \multicolumn{4}{|c|}{ Área(ha) por año } & \\
\hline & 1980 & 1996 & 2001 & Cambio $^{\dagger}$ & Porcentaje $^{\dagger}$ \\
\hline Cultivado & 7538 & 52822 & 86718 & 79180 & 1050.35 \\
\hline Inducido & 10001 & - & 40431 & 30430 & 304.27 \\
\hline \multirow{2}{*}{ Matorrales } & \multicolumn{4}{|c|}{ Área(ha) por año } & \\
\hline & 1980 & 1996 & 2001 & Cambio $^{\dagger}$ & Porcentaje $^{\dagger}$ \\
\hline Mezquital & 2173 & 280 & 729 & -1444 & -66.46 \\
\hline $\begin{array}{l}\text { Mezquital con vegetación } \\
\text { secundaria }\end{array}$ & 1389 & - & - & -1389 & -100 \\
\hline Matorral sarcocaule & 47799 & 36657 & 391 & -47408 & -99.18 \\
\hline $\begin{array}{l}\text { Matorral sarcocaule con } \\
\text { vegetación secundaria }\end{array}$ & 10249 & - & 10842 & 592 & 5.78 \\
\hline \multirow{2}{*}{ Bosques } & \multicolumn{5}{|c|}{ Área(ha) por año } \\
\hline & 1980 & 1996 & 2001 & Cambio $^{\dagger}$ & Porcentaje $^{\dagger}$ \\
\hline De pino & - & 30594.80 & 1186.67 & 1186.67 & 100 \\
\hline $\begin{array}{l}\text { De pino-encino (incluye } \\
\text { encino-pino) }\end{array}$ & 47019.82 & - & 20656.28 & -26363.55 & -56.07 \\
\hline $\begin{array}{l}\text { De pino-encino (incluye } \\
\text { encino-pino) con vegeta- } \\
\text { ción secundaria }\end{array}$ & - & - & 6516.51 & 6516.51 & 100 \\
\hline De encino & 25320.18 & 45213.38 & 29358.33 & 4038.16 & 15.95 \\
\hline $\begin{array}{l}\text { De encino con vegetación } \\
\text { herbácea y arbustiva }\end{array}$ & - & - & 10216.44 & 10216.44 & 100 \\
\hline \multirow{2}{*}{ Selvas } & \multicolumn{5}{|c|}{ Área(ha) por año } \\
\hline & 1980 & 1996 & 2001 & Cambio $^{\dagger}$ & Porcentaje $^{\dagger}$ \\
\hline $\begin{array}{l}\text { Baja caducifolia y subcadu- } \\
\text { cifolia }\end{array}$ & 364691.11 & 448239.10 & 280220.97 & -84470.15 & -23.16 \\
\hline $\begin{array}{l}\text { Baja caducifolia y subca- } \\
\text { ducifolia con vegetación } \\
\text { secundaria }\end{array}$ & 93414.83 & - & 98164.57 & 4749.74 & 5.08 \\
\hline Baja espinosa & - & 13269.37 & 31277.35 & 31277.35 & 100 \\
\hline
\end{tabular}




\begin{tabular}{|l|c|c|c|c|c|}
\hline $\begin{array}{l}\text { Baja espinosa con vegeta- } \\
\text { ción secundaria arbustiva } \\
\text { y herbácea }\end{array}$ & - & - & 11761.48 & 11761.48 & 100 \\
\hline \multicolumn{1}{|c|}{ Otros usos } & $\mathbf{1 9 8 0}$ & $\mathbf{1 9 9 6}$ & $\mathbf{2 0 0 1}$ & Cambio $^{\dagger}$ & Porcentaje $^{\dagger}$ \\
\cline { 2 - 7 } & - & - & 52.24 & 52.24 & 100 \\
\hline Sin vegetación aparente & - & - & 547.73 & 547.73 & 100 \\
\hline Asentamiento humano & 7963.32 & 5010.25 & 4747.48 & -3215.83 & -40.38 \\
\hline Cuerpo de agua & & & &
\end{tabular}

Nota: $†$ Cambio de 1980 a 2000.

\section{Conclusiones}

En el periodo de los años de 1980 al 2000 se encontró una dinámica de los tipos de uso del suelo y vegetación que se explica por efectos naturales o de la acción humana, que al utilizar los recursos vegetales de manera selectiva y de bajo impacto, desencadena cambios menores en los tipos de vegetación, que lleva a la desaparición de algunos tipos de vegetación por cambios en las condiciones en donde se desarrollaba.

Los cambios en el tipo de uso del suelo se presentan en la agricultura y la ganadería. La primera, disminuye en un $21 \%$ su superficie dedicada a esta actividad; en tanto que la segunda, incrementa de manera exponencial la superficie de pastos cultivados e inducidos, además de influir en menor medida en los otros tipos de uso. Esto se explica en términos de la importancia económica de la ganadería del municipio de Álamo, asociada a la producción de becerros al destete con fines de exportación, que en el periodo analizado llevó a incrementos de la superficies de pastos cultivados de más del 1000\%, y de pastos inducidos al $40 \%$.

Otro elemento a considerar sobre la importancia de estudiar el cambio de uso de suelo en el periodo propuesto en este estudio, es que en el territorio que ocupa el municipio de Álamos se encuentra el Área de Protección de Flora y Fauna (APFF), Sierra de ÁlamosRío Cuchujaqui, cuya superficie es de más de 92 mil hectáreas. Esta tiene la particularidad de conservar parte de las selvas bajas caducifolias y subcaducifolias ubicadas más al norte del continente, las cuales en esta área se entremezclan con el matorral espinoso, con los bosques de pino y encino y la vegetación riparia. Esta mezcla de ecosistemas da lugar a comunidades vegetales únicas de gran interés ecológico, además de los ecotonos que se generan por los gradientes ambientales en la transición de un tipo de vegetación a otro. Las cañadas que existen en el área tienen condiciones microclimáticas que pueden dar lugar a especies endémicas, por lo que este estudio pretende ser un referente para investigaciones sobre el cambio de uso del suelo en Álamos. 


\section{Referencias}

Bocco, G. et al. (2000). Ciencia, comunidades indígenas y manejo de recursos naturales. Un caso de investigación participativa en México. Interciencia, 25 (2), Caracas, pp. 64-70.

Bocco, G. et al. (2001). La dinámica del cambio de uso del suelo en Michoacán. Una propuesta metodológica para el estudio de los procesos de deforestación. Investigaciones Geográficas, Boletín núm. 44, Instituto de Geografía, UNAM, México, pp. 18-38.

Camacho, J. et al. (2011). Procesos y cambios de ocupación del suelo en un espacio geográfico de México 1976 y 1993. Revista Internacional de Ciencias de la Tierra. Mapping Centro América y el Caribe, pp 60-69.

Carabias, J. et al. (1994). Manejo de recursos naturales y pobreza rural. Universidad Nacional Autónoma de México-Comisión Federal de Electricidad. México. p. 137

Cotecoca (1974). Coeficientes de agostadero de la República Mexicana: Estado de Sonora. SAG. México, D. F.

De R., A.; Schmuck, G.; Perdigao, V. y Thielen, J. (2003). The influence of historic land use changes and future planned land use scenarios on floods in the Oder catchment. Physics Chem. Earth 28: pp. 1291-1300.

GeoCover (2000). Orthorectified Landsat Enhanced Thematic Mapper (ETM+) Compressed Mosaics. Applied Science Directorate. NASA Satellite Images. Image N-12-25-2000. Recuperado de: https://zulu.ssc.nasa.gov/mrsid/

Kummer, D.M. y Turner, B.L. (1994). The human causes of deforestation in Southeast Asia. Bioscience, Vol. 44, núm. 5, pp. 323-328.

Lambin, E.F. (1997). Modelling and monitoring land-cover change process in tropical regions. Progress in Physical Geography, Vol. 21, núm. 3, pp. 375-393.

Mas, J.F.; Velázquez, A. y Couturier, S. (2009). La evaluación de los cambios de cobertura/uso del suelo en la República Mexicana. Investigación ambiental. Ciencia y Política Pública 1:23-39.

Masera, O. (1996). Deforestación y degradación forestal en México. Documentos de trabajo \#19, GIRA A. C. Pátzcuaro, México. 
Masera, O. et al. (1997). Carbon emissions from Mexican forest: current situation and longterm scenarios. Climatic Change, núm. 35, pp. 265-295.

Medley, K. et al. (1995). Landscape change with agricultural intensification in a rural watershed, southwestern Ohio, USA. Landscape Ecology, Vol. 10, núm. 3, pp. 161-176.

México, Instituto Nacional de Estadística y Geografía (1993). Uso de suelo y vegetación. Serie II, escala 1:250 000 .

México, Instituto Nacional de Estadística y Geografía (1980). Uso de suelo y vegetación. Serie I, escala 1:250 000 .

México, Secretaría de Medio Ambiente y Recursos Naturales (2008). Informe de la situación del medio ambiente en México, Compendio de estadísticas ambientales.

México, Secretaría de Medio Ambiente y Recursos Naturales - UNAM (2001). Inventario Forestal Nacional 2000.

México, Secretaría de Desarrollo Urbano y Ecológico (1998). Ley general del equilibrio ecológico y la protección al ambiente. Nueva ley publicada en el Diario Oficial de la Federación el 28 de enero de 1988, texto vigente última reforma publicada, DOF 09012015.

Monterroso, A. et al. (2006). Análisis del cambio de uso del suelo del municipio de Tlalchapa, Guerrero, mediante el uso de imágenes de satélite, pp. 133-153. En Aguilar G (ed.) 2006. Los recursos naturales: diagnóstico y tecnología agroforestal. 1a. Ed. Universidad Autónoma Chapingo, p. 285

Nunnally, R.N. y Witmer, E.R. (1970). Remote sensing for land use studies. Photogrammetric engineering, vol. 36 (5), pp. 449-453.

Pan, D. et al. (1999). Temporal (1958-1993) and spatial patterns of land use changes in HautSaint-Laurent Quebec, Canada and their relation to landscape physical attributes. Landscape Ecology, núm. 14, pp. 35-52.

Ramírez, A.G. (2005). Programa de ordenamiento ecológico territorial del municipio de Álamos. Centro Regional Universitario del Noroeste. Obregón, Sonora, p. 455 
Sánchez, M. T. et al. (2013). La política de ordenamiento territorial en México: de la teoría a la práctica. Reflexiones sobre sus avances y retos a futuro, pp 19-47. En La política de ordenamiento territorial en México. Centro de Investigaciones en Geografía Ambiental (CIGA), Instituto de Geografía, UNAM, Instituto Nacional de Ecología y Cambio Climático. México D. F. p. 758

Skole, D.L. et al. (1994). Physical and human dimensions of deforestation in Amazonia. Bioscience, vol. 44, núm. 5, pp. 314-322.

Toledo, V. (1996). Los ejidos y comunidades, lugar de inicio del desarrollo sustentable en México. Revista de la Universidad de Guadalajara, núm. 6, pp. 28-33.

Trucíos, R. et al. (2011). Interpretación del cambio en vegetación y uso de suelo. Terra Latinoamericana. Octubre-diciembre, pp. 359-367.

Vásquez, A. (1996). El ordenamiento territorial y los cambios en el uso de la tierra en Costa Rica. Agronomía Costarricense 20 (1), pp. 87-94. 